\title{
New acute respiratory management in tracheal rupture caused by chest trauma
}

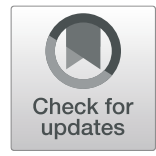

Cheng Shen and Lin Ma*

\begin{abstract}
We report a case who is a 33-year-old man admitted to our Emergency room for chest trauma caused by the factory's mechanical arm. Despite the endotracheal tube, the patient's respiratory state was poor and the oxygen saturation did not improve and the subcutaneous emphysema progressed. To improve distressed breathing, we first proposed the concept "mechanical ventilation with dual ventilator" to maintain oxygen saturation of the patient. This is, to our knowledge, the first report of using a special mechanical ventilation method in emergency surgery.
\end{abstract}

Keywords: Chest trauma, Tracheal rupture, Mechanical ventilation, Emergency surgery

A 33-year-old man was admitted to our Emergency Room for chest trauma caused by the factory's mechanical arm. He was a non-smoker. Physical examination revealed noticeable twist feeling under the skin of his neck, chest and abdomen. Plain chest computed tomography $(\mathrm{CT})$ revealed suspected damage to the right tracheal membrane of patient (Fig. 1a and b, red arrow) and multiple fractures of the bilateral ribs, including the anterior branch of the left first and second ribs, and the posterior branch of the ribs in the right side (3th, 5th, 6th and 7th). It also showed soft tissue swelling and subcutaneous emphysema in neck, anterior chest wall, back and abdomen. Mediastinum emphysema and bilateral lung contusion were existing in chest CT obviously. On both sides of the chest, pneumothorax with pleural effusion and bilateral drainage tube shadows were seen in chest images. His oxygen saturation level decreased to $80 \%$. However, due to the unstable condition of the patient and short time (less than $45 \mathrm{~min}$ ) for organizational reason in Emergency room, especially the mediastinum and subcutaneous emphysema of the whole body were

\footnotetext{
* Correspondence: malin_hx@163.com Department of Thoracic Surgery, West-China Hospital, Sichuan University, Chengdu 610041, China
}

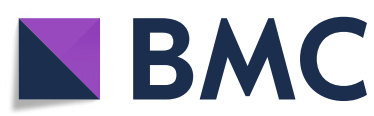

(c) The Author(s). 2020 Open Access This article is licensed under a Creative Commons Attribution 4.0 International License, which permits use, sharing, adaptation, distribution and reproduction in any medium or format, as long as you give appropriate credit to the original author(s) and the source, provide a link to the Creative Commons licence, and indicate if changes were made. The images or other third party material in this article are included in the article's Creative Commons licence, unless indicated otherwise in a credit line to the material. If material is not included in the article's Creative Commons licence and your intended use is not permitted by statutory regulation or exceeds the permitted use, you will need to obtain permission directly from the copyright holder. To view a copy of this licence, visit http://creativecommons.org/licenses/by/4.0/ The Creative Commons Public Domain Dedication waiver (http://creativecommons.org/publicdomain/zero/1.0/) applies to the data made available in this article, unless otherwise stated in a credit line to the data. aggravated in short time, there was no more time to arrange bronchoscopy and gastroscopy.

We approached the right chest via the thoracotomy with general anesthesia under double-lumen tube mechanical ventilation immediately. The patient's respiratory state was poor, and gas analysis of the arterial blood revealed a $\mathrm{pH}$ of $7.29, \mathrm{pO}_{2}$ of $50 \mathrm{mmHg}, \mathrm{pCO}_{2}$ of 51 $\mathrm{mmHg}$, and $65 \% \mathrm{O}_{2}$ saturation during the operation. Despite the endotracheal tube, the oxygen saturation did not improve and the subcutaneous emphysema progressed. Then we check the contralateral chest cavity through the anterior mediastinum to exclude the left pneumothorax for the suspicion on the chest tube occlusion. The main reason for poor oxygen saturation is severe left lung contusion. During intraoperative exploration and auxiliary observation by bronchoscope, we found that the tearing of tracheal membrane from the top of the right thorax down to the carina near the right main bronchus, and a $0.5 * 0.5 \mathrm{~cm}$ cavity was seen in the carina membrane. A diagnosis of tracheal rupture was made during the surgery. At the same time, as the patient was in the left lateral position during the operation, extracorporeal membrane oxygenator (ECMO) could not be placed. To improve distressed breathing, we proposed the concept "mechanical ventilation with 

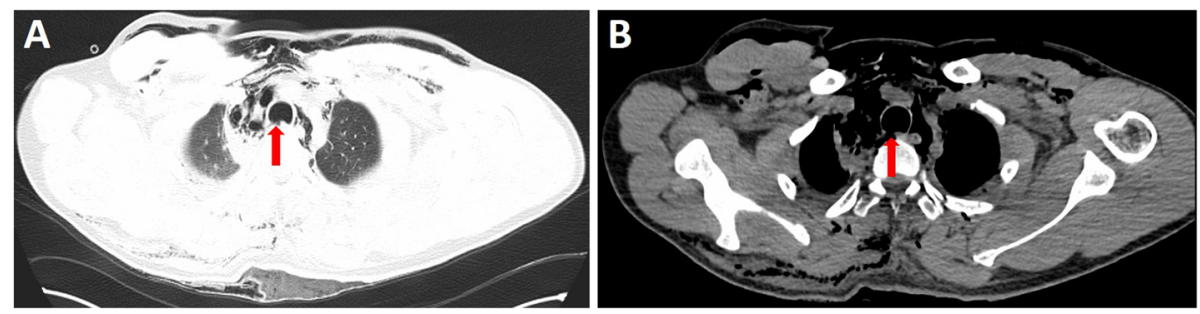

Fig. 1 Plain chest CT revealed suspected damage to the right tracheal membrane of patient (red arrow)

dual ventilator" to maintain oxygen saturation of the patient. Specifically, a $0.5 \mathrm{~cm}$ incision was made at the right intermediate bronchus, and a single lumen tube (5\#) was inserted to maintain ventilation of the right middle and lower lobes (Fig. 2). The PEEP, FiO2, tidal volumes and respiratory pressure of left lung were $6 \mathrm{cmH} 2 \mathrm{O}, 90 \%, 162 \mathrm{ml}$ $\left(6 \mathrm{ml} / \mathrm{kg}^{*} 60 \mathrm{~kg}^{*} 45 \%\right)$ and $20 \mathrm{cmH} 2 \mathrm{O}$ respectively. The PEEP, $\mathrm{FiO} 2$, tidal volumes and respiratory pressure of right lung were $5 \mathrm{cmH} 2 \mathrm{O}, 90 \%, 108 \mathrm{ml}\left(6 \mathrm{ml} / \mathrm{kg}^{*} 60 \mathrm{~kg} * 30 \%\right)$ and $20 \mathrm{cmH} 2 \mathrm{O}$ respectively. The oxygen saturation of patient was significantly improved, and maintained around 98\%.
During the operation, free myocutaneous flap of the right posterior chest wall pleura was formed to cover the defect of the carina (At the level T4 of the anastomosis, insert a pedicled pleural flap with the proximal trachea side not to be broken, approximately $4 \times 8 \mathrm{~cm}$ in size, and wrap the flap around the carina from back to front), and the remaining tracheal membrane was sutured with 3-0 sutures to repair the fracture. The patient was discharged 7 days after the operation with no complication.

This is, to our knowledge, the first report of using a special mechanical ventilation method in emergency

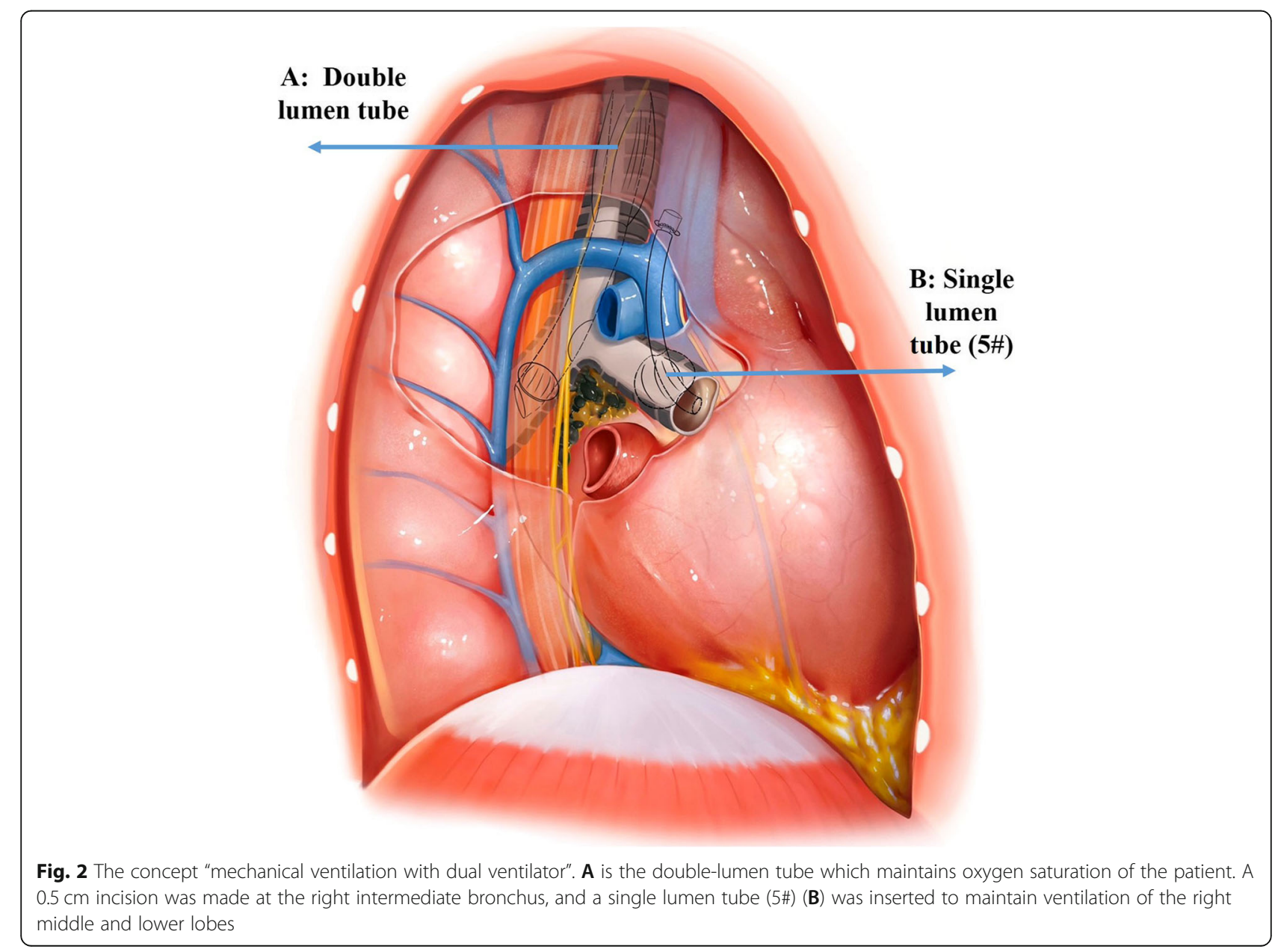


thoracic surgery. Tracheobronchial rupture from chest trauma is a potentially lethal injury [1]. In some cases, patients are not in a condition to safely perform bronchoscopy in emergency rooms [2, 3]. "Independent lung ventilation" has been used for some time in the ICU or operation room for regular surgery or ARDS [4-6].

In patients with mechanical ventilation, the cuff of the single lumen tube was placed distal of the laceration with sufficient reserve to the carina. If the laceration affected the tracheal bifurcation or the right or left main stem bronchus, the opposite bronchus was intubated with a corresponding double-lumen tube $[7,8]$. However, in our case, the patients was intubated with double-lumen tube, but the left single lung ventilation cannot be maintained in surgery. So we proposed innovative ventilation method called "mechanical ventilation with dual ventilator". The reasons for the application include the critical condition of the patient without the result of bronchoscopy and gastroscopy before the operation. Secondly, the poor single lung ventilation cannot be maintained in surgery and pneumothorax should be excluded; the application of ECMO in the lateral position during thoracic surgery also faces difficulties. The application of the "mechanical ventilation with dual ventilator" is simple, practical and efficient method, which effectively solves the state of hypoxic saturation of patients, and it can be applied in a timely manner in future emergency thoracic surgery.

\section{Acknowledgements}

We greatly appreciate the assistance of the staff of the Department of Thoracic Surgery, West-China Hospital, Sichuan University, and thank them for their efforts.

\section{Authors' contributions}

CS was involved in drafting the manuscript and analysis of the data. LM designed and revised the manuscript. The authors have read and approved the final manuscript.

\section{Funding}

None.

\section{Availability of data and materials}

All data for this study are publicly available and are ready for the public from database of hospital.

Ethics approval and consent to participate Not applicable.

\section{Consent for publication}

All the authors consent to publish the paper.

\section{Competing interests}

The authors have no conflicts of interest to declare.

Received: 15 July 2020 Accepted: 3 September 2020

Published online: 12 September 2020

\section{References}

1. Kramer S, Broschewitz J, Kirsten H, Sell C, Eichfeld U, Struck MF. Prognostic factors for iatrogenic tracheal rupture: a single-center retrospective cohort study. J Clin Med. 2020;9(2):382.
2. Khitaryan Capital AC, Miziev I, Veliev C, Voronova O, Golovina A, Zavgorodnyaya $\mathrm{R}$, et al. Case report of successful management of intraoperative tracheal rupture during thoracoscopic esophageal resection in patient with esophageal cancer. Int J Surg Case Rep. 2019;57:42-6.

3. Struck MF, Hempel G, Pietsch UC, Broschewitz J, Eichfeld U, Werdehausen R, et al. Thoracotomy for emergency repair of iatrogenic tracheal rupture: single center analysis of perioperative management and outcomes. BMC Anesthesiol. 2019;19(1):194.

4. Yoshida M, Taira Y, Ozaki M, Saito H, Kurisu M, Matsushima S, et al. Independent lung ventilation with use of a double-lumen endotracheal tube for refractory hypoxemia and shock complicating severe unilateral pneumonia: a case report. Respir Med Case Rep. 2020;30:101084.

5. Berg S, Bittner EA, Berra L, Kacmarek RM, Sonny A. Independent lung ventilation: implementation strategies and review of literature. World I Crit Care Med. 2019:8(4):49-58.

6. Minhas JS, Halligan K, Dargin JM. Independent lung ventilation in the management of ARDS and bronchopleural fistula. Heart Lung. 2016;45(3): 258-60.

7. Invencio da Costa LF, Alzate Amaya F, Barreto Calvo PC, Gonzalez Poggioli N. Tracheal rupture after orotracheal intubation, based on a clinical case. Rev Esp Anestesiol Reanim. 2019;66(5):296-7.

8. Bozzo C, Profili S, Masala S. Successful use of self-expandable metal stents in a case of iatrogenic tracheal rupture. Radiol Case Rep. 2019;14(3):377-80.

\section{Publisher's Note}

Springer Nature remains neutral with regard to jurisdictional claims in published maps and institutional affiliations. 